\title{
Stable nuclear transformation of Pandorina morum
}

\author{
Kai Lerche and Armin Hallmann*
}

\begin{abstract}
Background: Volvocine green algae like Pandorina morum represent one of the most recent inventions of multicellularity diverged from their unicellular relatives. The 8-16 celled P. morum alga and its close multicellular relatives constitute a model lineage for research into cellular differentiation, morphogenesis and epithelial folding, sexual reproduction and evolution of multicellularity. Pandorina is the largest and most complex organism in the volvocine lineage that still exhibits isogamous sexual reproduction. So far, molecular-biological investigations in P. morum were constricted due to the absence of methods for transformation of this species, which is a prerequisite for introduction of reporter genes and (modified) genes of interest.

Results: Stable nuclear transformation of $P$. morum was achieved using chimeric constructs with a selectable marker, a reporter gene, promoters and upstream and downstream flanking sequences from heterologous sources. DNA was introduced into the cells by particle bombardment with plasmid-coated gold particles. The aminoglycoside 3'-phosphotransferase VIII (aphVIII) gene of Streptomyces rimosus under control of an artificial, heterologous promoter was used as the selectable marker. The artificial promoter contained a tandem arrangement of the promoter of both the heat shock protein 70A (hsp70A) and the ribulose-1,5-bisphosphat-carboxylase/-oxygenase S3 (rbcS3) gene of Volvox carteri. Due to the expression of aphVIII, transformants gained up to 333-fold higher resistance to paromomycin in comparison to the parent wild-type strain.

The heterologous luciferase (g/uc) gene of Gaussia princeps, which was previously genetically engineered to match the nuclear codon usage of Chlamydomonas reinhardtii, was used as a co-transformed, unselectable reporter gene. The expression of the co-bombarded gluc gene in transformants and the induction of gluc by heat shock were demonstrated through bioluminescence assays.

Conclusion: Stable nuclear transformation of $P$. morum using the particle bombardment technique is now feasible. Functional expression of heterologous genes is achieved using heterologous flanking sequences from Volvox carteri and Chlamydomonas reinhardtii. The aphVIII gene of the actinobacterium S. rimosus can be used as a selectable marker for transformation experiments in the green alga P. morum. The gluc gene of the marine copepod G. princeps, expressed under control of heterologous promoter elements, represents a suitable reporter gene for monitoring gene expression or for other applications in P. morum.
\end{abstract}

Keywords: Co-transformation, Gaussia princeps luciferase gene, Genetic engineering, Green algae, Heterologous expression, Reporter genes, Selectable markers, Streptomyces rimosus aphVIII gene, Volvocaceae, Volvocine algae

\footnotetext{
* Correspondence: armin.hallmann@gmx.de

Department of Cellular and Developmental Biology of Plants, University of

Bielefeld, Universitätsstr. 25, D-33615 Bielefeld, Germany
} 


\section{Background}

The volvocine green algae, a group of $\sim 50$ species involving the families Chlamydomonaceae, Goniaceae and Volvocaceae [1], serve as a model lineage for research into cellular differentiation, morphogenesis, epithelial folding and evolution of multicellularity [2-4]. Furthermore, this group is used to study the evolution of sexual reproduction, including the evolution of anisogamy [2,5]. In many lineages, like higher plants and animals, the evolution of multicellularity and sexual reproduction occurred way back in evolutionary history and the molecular origins therefore are obscured by genetic drift. In the volvocine algae the development from unicellular species, which were similar to the present species Chlamydomonas reinhardtii [5], to multicellular species and its relatives occurred only about 200 million years ago [1]. Well-known multicellular species in this group are Volvox, Pleodorina, Eudorina, Pandorina and Gonium [2,4]. The 8-16 celled Pandorina morum (Figure 1) [6,7] is intermediate in organizational complexity between the unicellular alga $C$. reinhardtii and the multicellular alga Volvox carteri (2,000-4,000 cells) and it has not been subject to molecular analyses and genetic engineering due to a lack of biotechnological possibilities.

The cells of $P$. morum form an ellipsoid spheroid with a distinct anterior-posterior polarity. The way of vegetative reproduction and mode of daughter colony formation where the young colonies break out of the old parental

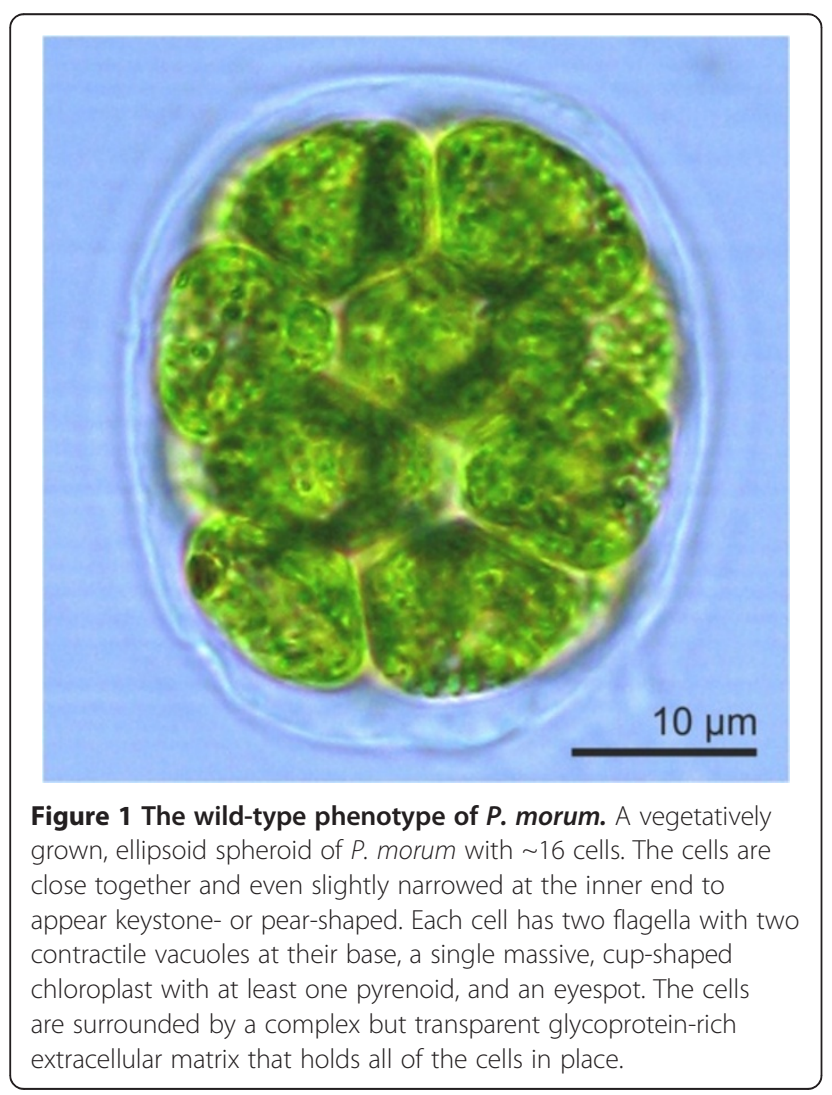

layers reminded Bory of the legend of Pandora's box; thus, he applied the French diminutive, Pandorina, to the genus he named [7]. There are several distinctive features of Pandorina that warrant its inclusion in the series of volvocine algae to be analyzed molecularly in the future. Pandorina has a special morphology among the volvocine algae: the cells fill nearly the entire volume of the colony, as opposed to other, larger volvocine algae in which the cells are arranged at the periphery of the colony, with extracellular matrix filling the space between cells. The compact morphology characteristic of Pandorina (Figure 1) appears to be derived from ancestors with expanded ECM [8]. Furthermore, Pandorina is the smallest volvocine alga to exhibit a 'colonial boundary', the tripartite boundary that surrounds the entire colony. This 'colonial boundary' is the most conserved morphological feature of the Volvocalean extracellular matrix [9]. Pandorina is moreover the largest and most complex organism in the volvocine lineage that still exhibits isogamous sexual reproduction $[2,4]$. Thus, the gametes of $P$. morum are almost identical in morphology, differing genetically only in allele expression in the mating-type locus (mating type plus or minus) [10]. The molecular-biological investigation and the comparison of molecular characteristics between the isogamous sexual reproduction in P. morum and anisogamous species like Eudorina could reveal insights into the evolution of anisogamy, but such studies are hampered by the absence of methods for genetic engineering of P. morum. In contrast, the anisogamous species Eudorina is accessible for genetic manipulations [11]. The technical feasibility of genetically manipulating a species of interest is a key factor for any detailed molecular analysis of gene or protein functions.

The nuclear genome of $P$. morum has not been sequenced, only its mitochondrial genome has been revealed [12]. Actually, only the genomes of C. reinhardtii [13] and $V$. carteri [14] have been sequenced in the group of volvocine algae. For both species effective transformation protocols exist and they are accessible to molecular manipulations [15-19]. Nuclear transformation protocols also exist for the volvocine algae Gonium pectorale [20] and Eudorina elegans [11]. There is a single transformation technique that worked in all of the previously transformed volvocine species, namely particle bombardment.

Aside from the nuclear transformation protocol, selectable markers and reporter genes are required for genetic manipulations. In the volvocine algae, selectable markers and reporter genes have mainly been established for C. reinhardtii [5,21-28] and, to a lesser extent, for V. carteri [28-31], G. pectorale [20] and E. elegans [11]. In the present study, we wanted to check whether the vectors and transformation methods that were developed earlier for volvocine algae - in particular those for G. pectorale [20] and E. elegans [11] - can be applied with equal success to Pandorina. 
The most promising candidate for a selectable marker gene in Pandorina was the aphVIII gene of Streptomyces rimosus that has been used as a selectable marker in C. reinhardtii [25], V. carteri [30,31], G. pectorale [20] and E. elegans [11]. The aphVIII gene codes for an aminoglycoside 3 '-phosphotransferase enzyme that catalyzes the transfer of the $\gamma$-phosphate of ATP to the 3 '-position of an aminoglycoside antibiotic like paromomycin; this transfer chemically modifies and inactivates the antibiotic molecule. Paromomycin otherwise inhibits cell growth by blocking the protein synthesis of ribosomes at the translocation stage [32].

The best candidate for a useful reporter gene in P. morum seemed to be the luciferase gene ( $g l u c$ ) of the deep sea copepod Gaussia princeps [33,34], which was previously adapted to the nuclear codon usage of $C$. reinhardtii [27]. The Gluc protein catalyzes the oxidation of the substrate coelenterazine into the excited form of coelenteramide that releases a photon with a wavelength of $480 \mathrm{~nm}$ upon electron transition to the ground state [34]. The blue light produced by this reaction can be detected by various methods like luminometer measurements and assays on light sensitive films [35]. The gluc reporter gene has successfully been introduced into C. reinhardtii [27], G. pectorale [20] and E. elegans [11] and it was functionally expressed in all three organisms.

The selectable markers and reporter genes also require appropriate promoters. Based on previous results, promising candidates were the $C$. reinhardtii promoter of the abundant protein of photosystem I complex gene (PSAD) [36], the C. reinhardtii promoter of the heat shock protein 70A (HSP70A) [37], and the V. carteri tandem promoter of the $h s p 70 \mathrm{~A}$ and $r b c \mathrm{~S} 3$ genes [31]. The C. reinhardtii HSP70A promoter and the $V$. carteri $h s p 70 \mathrm{~A} / r b c \mathrm{~S} 3$ tandem promoter have already proved useful for expression of the aphVIII gene in V. carteri, C. reinhardtii, G. pectorale and E. elegans $[11,20,30]$.

Here we demonstrate the stable nuclear transformation of $P$. morum using chimeric constructs containing heterologous aphVIII and gluc genes under the control of heterologous 5' and 3' flanking sequences from V. carteri and C. reinhardtii. The enzyme activity of the heterologously expressed Gaussia luciferase was detectable by luminometer measurements and bioluminescence assays. The expression of the heterologous gluc gene was further increased in transformants containing the gluc gene under control of the heterologous tandem promoter including the heat shock promoter, if the transformants were subject to a temporary shift to higher temperatures.

\section{Results}

Antibiotic tolerance of wild-type Pandorina algae To allow for selection of transformants with even weak transgene-mediated resistance, the lowest concentration of the antibiotic paromomycin that kills all wild-type Pandorina cells was determined. To achieve this, a series of aliquots with the same number of wild-type $P$. morum cells was exposed to increasing concentrations of paromomycin, incubated for 10 days, and screened for living (green) or dead (white) cells. The alga P. morum tolerated concentrations of up to $0.15 \mu \mathrm{g} / \mathrm{ml}$ paromomycin. A concentration of $0.20 \mu \mathrm{g}$ paromomycin $/ \mathrm{ml}$ or higher led to $100 \%$ cell death (Figure 2A). To allow for an objective and rapid discrimination between aliquots containing living cells and aliquots containing dead cells even in large-scale screenings of culture plates, red-shifted falsecolor images were created from standard photographs of the plates (Figure 2A, right panel). Red-shifting makes living cells much easier to distinguish from dead cells.

\section{Transformation experiments using aphVIII as a selectable marker}

The establishment and optimization of the transformation protocol was done by changing several parameters systematically (Additional file 1). In the most successful protocol, $150 \mathrm{ml}$ of a logarithmically growing $P$. morum culture with a density of $7 \times 10^{4}$ cells $/ \mathrm{ml}$ was harvested by centrifugation. The concentrated algae were spread and immobilized on a cellulose acetate membrane filter and subjected to particle bombardment. The total number of cells used for each transformation experiment was about $9 \times 10^{6}$. Different settings of the Biolistic PDS1000/He (Bio-Rad) particle delivery system were tested to obtain the maximum number of paromomycin resistant transformants (Additional file 1). The most effective protocol for the biolistic transformation of $P$. morum using DNA-coated gold microprojectiles is described in the Materials and Methods section. The parameters for the most effective transformation protocol are summarized in Table 1.

For all transformation experiments, a chimeric, aphVIIIbased plasmid (pPmr3) [31] was used as a selectable marker that confers resistance to paromomycin. The pPmr3 plasmid contains the coding sequence of the Streptomyces rimosus aphVIII gene, a 5 -flanking sequence that includes an artificial tandem promoter from the $h s p 70 \mathrm{~A}$ and $r b c \mathrm{~S} 3$ genes of $V$. carteri, and a 3 '-flanking sequence derived from the $r b c \mathrm{~S} 3$ gene of $V$. carteri (Figure 3A) [11,20].

Unselectable plasmids were co-transformed with the selectable marker plasmid pPmr3. For use as a reporter gene, the gluc gene was brought under control of different heterologous $5^{\prime}$ and $3^{\prime}$ flanking sequences from $V$. carteri and $C$. reinhardtii. The utilized plasmids were pPsaDGLuc, pHsp70A-GLuc or pHRLucP (Figure 3B-D) [11,20]. After the transformation procedure, the algae were incubated in liquid medium and allowed to recover for $24 \mathrm{~h}$ before paromomycin was added. Within $48 \mathrm{~h}$ all nontransformed algae died, which resulted in a temporary 


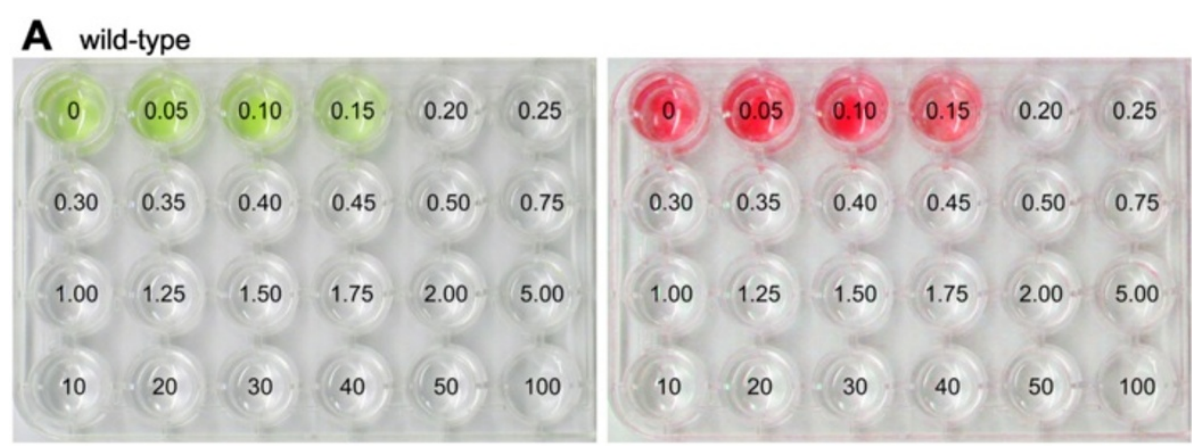

\section{B transformant PanTJ-5}

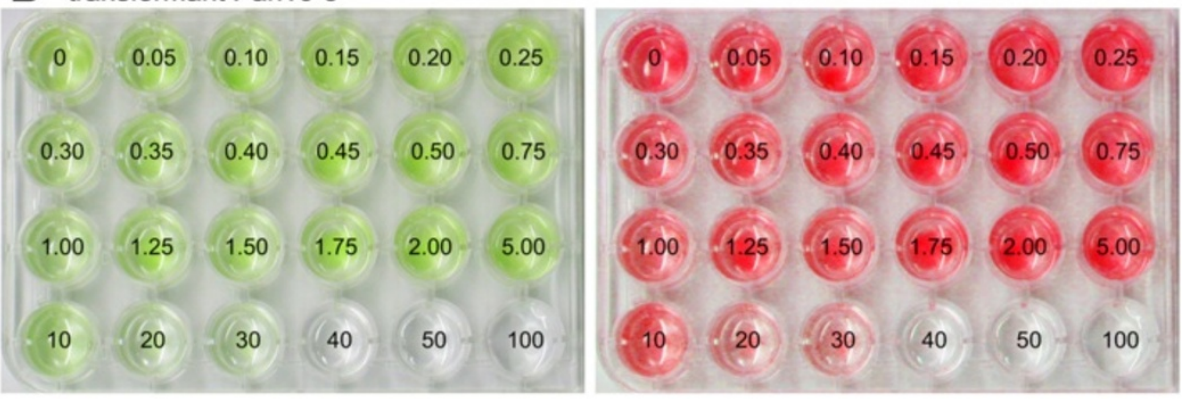

\section{C transformant PanHR-5}

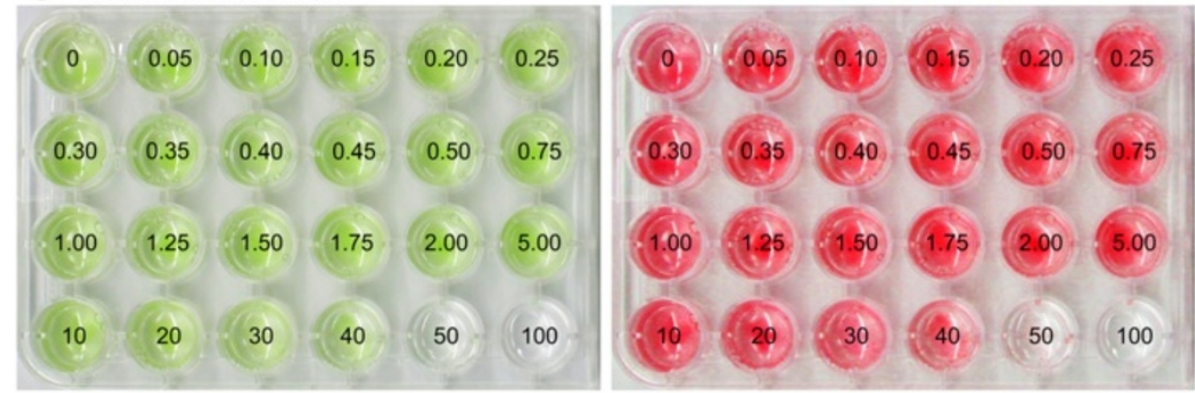

\section{D transformant PanHsp-8}

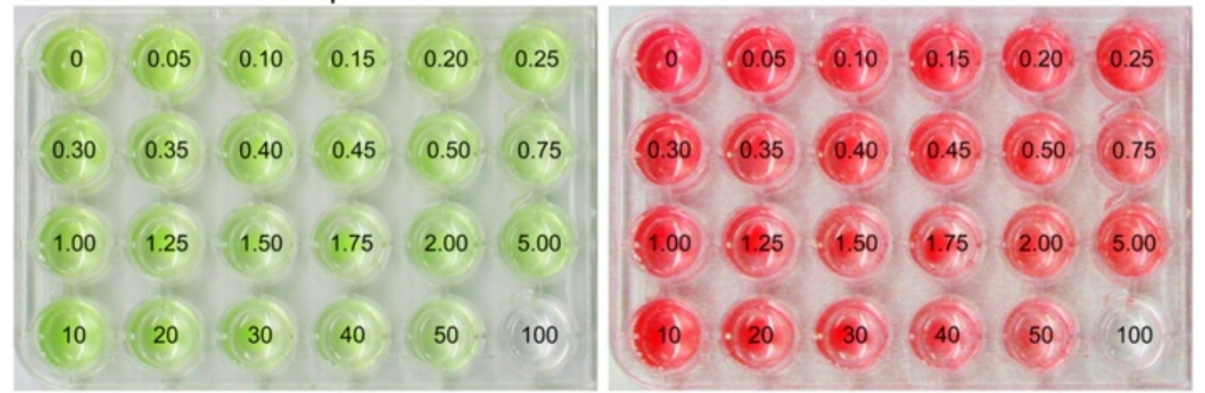

Figure 2 Analysis of paromomycin resistance in wild-type and transgenic $\boldsymbol{P}$. morum strains. For detailed analysis of resistance, identical quantities of $P$. morum cells were exposed to increasing concentrations of paromomycin, and incubated for 10 days. Numbers refer to the concentration of paromomycin $[\mathrm{\mu g} / \mathrm{ml}]$ utilized. Natural color (left) and red-shifted, false-color images (right) are shown. (A) The wild-type P. morum strain. (B-D) Transgenic P. morum strains co-transformed with pPmr3, the selectable marker plasmid, in addition to a second, non-selectable reporter gene plasmid. (B) Transformant PanTJ-5 was co-transformed with the plasmids pPmr3 and pPsaD-GLuc. (C) Transformant PanHR-5 was co-transformed with the plasmids pPmr3 and pHRLucP. (D) Transformant PanHsp-8 was co-transformed with the plasmids pPmr3 and pHsp70A-GLuc. 
Table 1 Most successful combination of parameters for $P$. morum transformation using a PDS-1000/He biolistic device

\begin{tabular}{ll}
\hline Parameter & Parameter specification \\
\hline Material of microprojectiles & gold \\
Size of microprojectiles & $0.6 \mu \mathrm{m}$ in diameter \\
Selectable marker plasmid & $\mathrm{pPmr} 3$ \\
Coating of microprojectiles & plasmid-DNA/microcarrier/ \\
& $\mathrm{CaCl}_{2} /$ spermidine/ ethanol \\
& - precipitation \\
Target cells & immobilized on cellulose \\
& acetate membrane filter; \\
Burst pressure of rupture disk & almost free of liquid \\
Rupture disk-macrocarrier distance & 1350 psi \\
Macrocarrier-stopping screen distance & $7 \mathrm{~mm}$ \\
Stopping screen-target cell distance & $8 \mathrm{~mm}$ \\
Chamber evacuation & $27 \mathrm{~cm}$ \\
Cultivation after particle bombardment & in liquid medium \\
\hline
\end{tabular}

clarification of the medium. After 10-14 days of incubation, re-greening of the incubation flasks indicated the initial presence and reproduction of at least one paromomycin-resistant transformant per flask. Using this protocol, a total of 38 paromomycin resistant clones were obtained in 4 independent transformation experiments.

\section{Paromomycin resistance of transformants}

The antibiotic resistance of the 38 transformants was justified and concretized by incubation for 10 days in $1 \mathrm{ml} \mathrm{JM}$ medium with different concentrations of paromomycin ranging from 0.05 to $100 \mu \mathrm{g} / \mathrm{ml}$ (for concentrations see Figure 2). Transformants with the most robust resistance tolerated concentrations up to $50 \mu \mathrm{g} / \mathrm{ml}$ paromomycin (Figure 2B-D, Table 2). Thus, transformants of $P$. morum generated with the selectable marker plasmid pPmr3 exhibit an up to 333-fold higher tolerance to paromomycin than the wild-type strains. The variation in resistance between different clones is quite common in transformation experiments $[11,20]$. This could be the result of genedosage effects caused by variable number of copies integrated into the genome and/or it can reflect position effects on expression of the transgene due to its random integration into the genome.

\section{Stable genomic integration and expression of the artificial aphVIII gene}

PCR was used to verify the stable integration of the pPmr3 vector with the artificial aphVIII gene into the genome of $P$. morum transformants. The artificial aphVIII gene was driven by the $V$. carteri hsp $70 \mathrm{~A} / r b c \mathrm{~S} 3$ tandem promoter and it confers resistance to paromomycin.
Genomic DNA was isolated from the 38 transformants about 100 generations after the transformants had been generated. The isolated DNA was used as a template for PCR and a 324 bp chimeric fragment of genomic DNA, containing $107 \mathrm{bp}$ of the $r b c \mathrm{~S} 3$ promoter region and $217 \mathrm{bp}$ of the aphVIII coding region, was expected to be amplified with the corresponding specific primers. PCR fragments of the expected size were obtained from many clones (Figure 4A-C); the fragments were cloned and sequenced (Figure $4 \mathrm{E}$ ). In Figures $4 \mathrm{~B}$ and $4 \mathrm{C}$ the lanes for the transformants PanHR-4, PanHR-10, PanHsp-2, PanHsp-9, PanHsp-10 and PanHsp-11 show no or only weak bands, which might reflect disturbance of the PCR reaction caused by too small DNA amounts, impurities of the genomic DNA or other reasons. Anyway, the repetition of the PCRs with fresh DNA isolates from these six clones yielded fragments of the expected size (data not shown). Moreover, growth of all 38 transformants in the presence of antibiotic already demonstrated the functional expression of the aphVIII gene (Figure 2, Table 2).

In addition to the provided indirect evidence of aphVIII expression through the mediated antibiotic resistance in transformants, the transcription of the aphVIII gene was also examined directly by RT-PCR analysis. For it, RNA from paromomycin-resistant transformants was reverse transcribed, and products were amplified by PCR using aphVIII specific primers. A cDNA fragment with 324 bp was expected. Actually, a PCR fragment of the expected size was obtained from all investigated paromomycin-resistant transformants, but not from the wild-type (Figure 4D). The amplified fragments were cloned and sequenced (Figure 4E).

\section{Calculation of transformation frequency}

The transformation frequency was calculated as the ratio of transformants that exhibited both resistance against paromomycin and the correct aphVIII fragment following PCR and the total number of cells used for each transformation experiment $\left(9 \times 10^{6}\right.$ cells $)$. Based on the results of 4 independent transformation experiments, a transformation frequency of $1.2 \times 10^{-6}$ per cell was calculated. This corresponds to a transformation frequency of about $1.9 \times 10^{-5}$ per organism.

\section{Plasmids for co-transformation with non-selectable reporter gene constructs}

To investigate the efficiency of co-transformation in P. morum, three different plasmids were used containing the gluc gene of G. princeps, which was previously engineered to match the codon usage of $C$. reinhardtii [27].

Plasmid pPsaD-GLuc contains the gluc gene under control of $5^{\prime}$ and $3^{\prime}$ control elements of the PSAD gene of C. reinhardtii $[27,36]$ (Figure $3 \mathrm{~B})$. In three volvocine species, i.e., C. reinhardtii, G. pectorale and E. elegans, the 
A
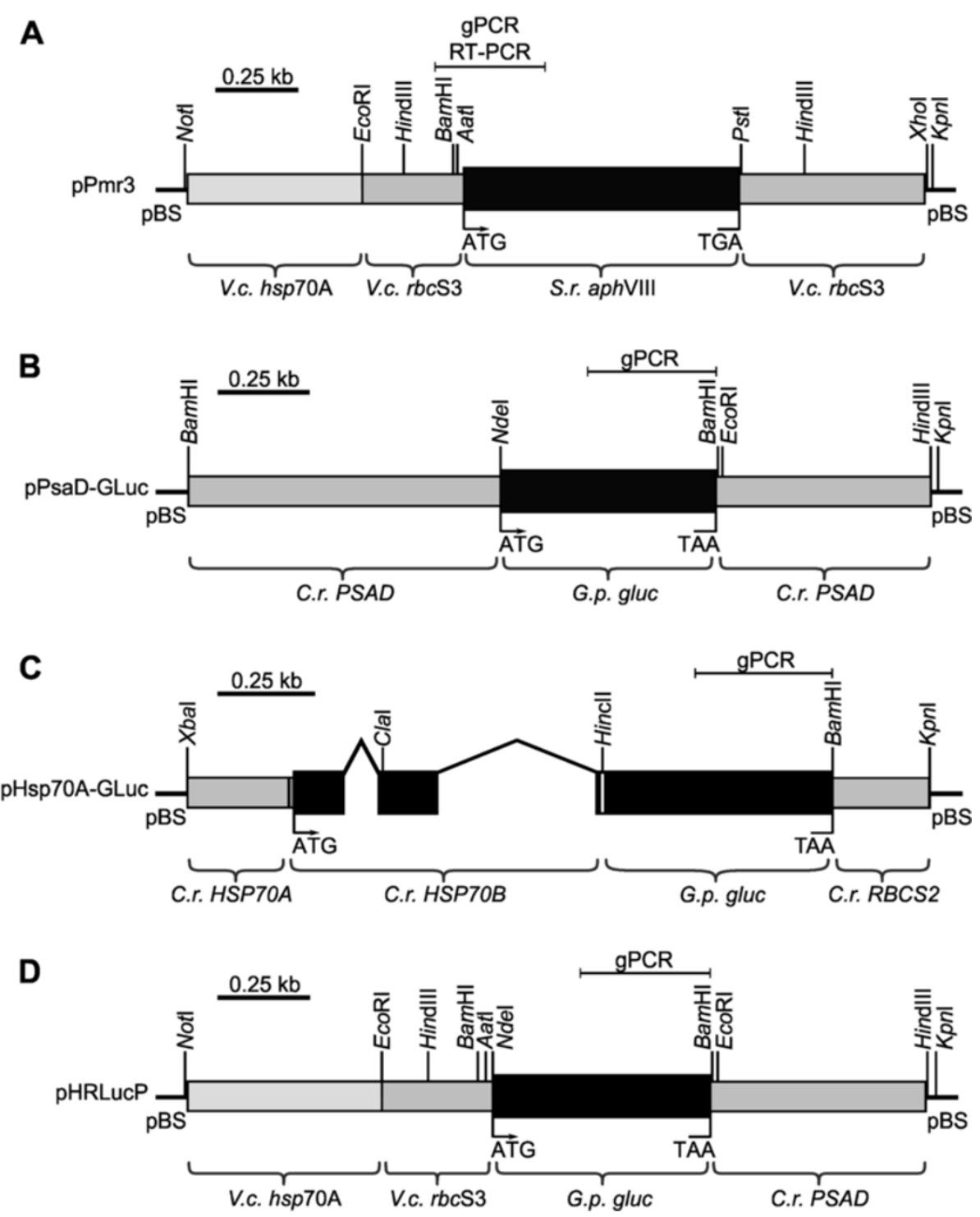

Figure 3 Schematic diagram of the selectable marker plasmid and co-transformed, non-selectable plasmids. (A) The chimeric selectable marker plasmid pPmr3. (B-D) Co-transformed, non-selectable plasmids containing reporter genes: (B) pPsaD-GLuc, (C) pHsp70A-GLuc, and (D) pHRLucP. The angled lines in (C) indicate introns. (A-D) Amplified genomic (gPCR) or RT-PCR fragments are indicated. V.c., Volvox carteri; C.r., Chlamydomonas reinhardtii; S.r., Streptomyces rimosus; G.p., Gaussia princeps; gluc, luciferase gene; pBS, pBluescript II vector.

PSAD promoter was shown to mediate strong expression $[11,20,27]$.

Plasmid pHsp70A-GLuc [11,20,27] (Figure 3C) contains the gluc gene flanked by the C. reinhardtii HSP70A 5'UTR and the RBCS2 3'UTR of C. reinhardtii. The HSP70A promoter was shown to mediate not only strong but also heatinducible expression. The plasmid also contains the first three exons and two introns of the C. reinhardtii $H S P 70 B$ gene that codes for the chloroplast transit peptide of the HSP70B protein $[27,38,39]$.

Except for flanking sequences of $C$. reinhardtii, we also tested flanking sequences of $V$. carteri. Plasmid pHRLucP contains the coding region of the gluc gene fused to a $\mathrm{V}$. carteri hsp70A/rbcS3 tandem promoter and a C. reinhardtii PSAD 3'UTR (Figure 3D). Like in plasmid pHsp70A-GLuc, the tandem promoter should mediate not only strong but also heat-inducible expression.

\section{Stable integration of non-selectable reporter gene constructs into the genome}

Transformants were generated by co-transformation with the selectable pPmr3 plasmid and one of the three gluc-derived, non-selectable reporter gene plasmids at a time. The obtained transformants were screened for stable 
Table 2 Results of paromomycin resistance assays*

\begin{tabular}{|c|c|c|c|c|c|}
\hline Transformant & $\begin{array}{c}\text { Resistance up to } \times \mu \mathrm{g} / \mathrm{ml} \\
\text { paromomycin }\end{array}$ & Transformant & $\begin{array}{c}\text { Resistance up to } \times \mu \mathrm{g} / \mathrm{ml} \\
\text { paromomycin }\end{array}$ & Transformant & $\begin{array}{c}\text { Resistance up to } \times \mu \mathrm{g} / \mathrm{ml} \\
\text { paromomycin }\end{array}$ \\
\hline PanTJ-1 & 50 & PanHR-1 & 50 & PanHsp-1 & 40 \\
\hline PanTJ-2 & 50 & PanHR-2 & 50 & PanHsp-2 & 50 \\
\hline PanTJ-3 & 50 & PanHR-3 & 40 & PanHsp-3 & 50 \\
\hline PanTJ-4 & 50 & PanHR-4 & 50 & PanHsp-4 & 50 \\
\hline PanTJ-5 & 30 & PanHR-5 & 40 & PanHsp-5 & 50 \\
\hline PanTJ-6 & 40 & PanHR-6 & 30 & PanHsp-6 & 40 \\
\hline PanTJ-7 & 50 & PanHR-7 & 40 & PanHsp-7 & 40 \\
\hline PanTJ-8 & 40 & PanHR-8 & 40 & PanHsp-8 & 50 \\
\hline PanTJ-9 & 40 & PanHR-9 & 40 & PanHsp-9 & 50 \\
\hline \multirow[t]{7}{*}{ PanTJ-10 } & 40 & PanHR-10 & 40 & PanHsp-10 & 50 \\
\hline & & PanHR-11 & 50 & PanHsp-11 & 50 \\
\hline & & PanHR-12 & 50 & PanHsp-12 & 40 \\
\hline & & PanHR-13 & 50 & & \\
\hline & & PanHR-15 & 50 & & \\
\hline & & PanHR-21 & 40 & & \\
\hline & & PanHR-22 & 40 & & \\
\hline
\end{tabular}

*tolerance of the wild-type strain P. morum SAG 32.96: $0.15 \mu \mathrm{g} / \mathrm{ml}$ paromomycin.

integration of the reporter gene constructs by PCR. For it, a PCR reaction was performed using genomic DNA of transformants as a template and gluc-specific oligonucleotides. The expected fragment was $342 \mathrm{bp}$ in size. Such a fragment was obtained from transformants produced by co-transformation with the plasmids pPsaD-GLuc (7 positive transformants), pHRLucP (16 positive transformants) and pHsp70A-GLuc (10 positive transformants) (Figure 5A-C). As expected, PCRs with genomic DNA of the wild-type yielded no such product. The identity of the amplified fragments was verified by cloning and sequencing (Figure 5D). Based on the results of the PCR experiments, the co-transformation rate in P. morum was determined to be $84 \%( \pm 15 \%)$. The co-transformation rate was defined as the rate of transformants containing the gluc gene among the transformants containing the aphVIII gene.

\section{Functional expression of co-transformed reporter genes}

Transformants generated by co-transformation with the selectable marker plasmid pPmr3 and the gluc-derived plasmids pPsaD-GLuc, pHRLucP and pHsp70A-GLuc were assayed for functional expression of luciferase. For it, cell extracts of all transformants were checked for luciferase activity using a luminometer (Figure 6A-C).

For some reason, no significant luciferase activity was observed in transformants generated with pPsaD-GLuc (Figure 6A). The relative light units (rlu) detected in these transformants are about the same as in wild-type cells and correspond to the background light, which is at about 1,000 rlu.
In contrast, luciferase activity was detected in several transformants generated by co-transformation with the plasmid pHRLucP (Figure 6B). In this DNA construct the gluc gene is under control of the artificial tandem promoter from the $h s p 70 \mathrm{~A}$ and $r b c \mathrm{~S} 3$ genes of $V$. carteri. Extracts of ten out of sixteen transformants clearly showed emission of light and, thus, functional expression of luciferase. The amount of detected relative light units (rlu) is significantly higher than in the wild-type strain $(853 \pm 11$ rlu). The transformants PanHR-9 and PanHR-11 exhibited the highest Gluc activity with 407,500 $\pm 45,000 \mathrm{rlu}$ and $378,500 \pm 57,000 \mathrm{rlu}$, respectively.

Extracts of transformants generated by co-transformation with the plasmid pHsp70A-GLuc showed a significant but mostly moderate luciferase activity when cultivated under standard conditions at $29^{\circ} \mathrm{C}$ (Figure 6C). In this DNA construct the gluc gene is under the control of the C. reinhardtii HSP70A promoter; there is also the genomic sequence of the $C$. reinhardtii HSP7OB chloroplast transit peptide containing two introns that precedes the gluc coding sequence. Only transformant PanHsp-4 exhibited a high Gluc activity of $786,000 \pm 20,000$ rlu under these conditions, while the wild-type strain showed only $966 \pm 50 \mathrm{rlu}$.

The DNA constructs in pHRLucP and pHsp70A-GLuc are driven by heat-shock promoters that show inducibility by heat in their donor organisms $V$. carteri and $C$. reinhardtii, respectively.

Analysis for inducibility of these promoter elements in P. morum was done by subjecting the algae transformed with the plasmids pHRLucP and pHsp70A-GLuc to a 

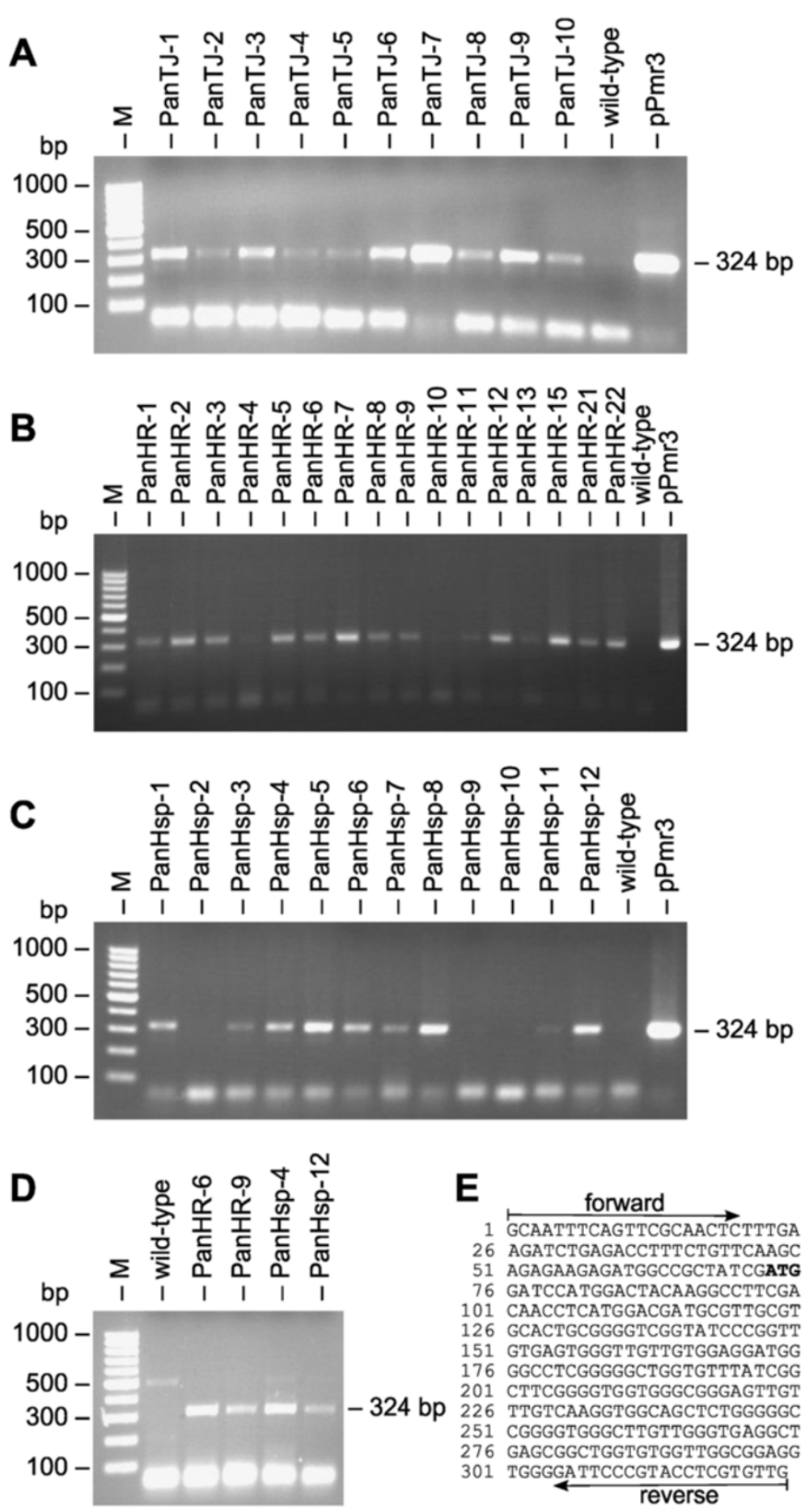

Figure 4 Detection of the aphVIII gene in transformants and demonstration of its transcription. (A-C) Paromomycin resistant transformants and the parental wild-type strain were analyzed for presence of the aphVIII gene in the genome by genomic PCR. The expected size of the PCR fragment produced in transformants was 324 bp (Figure 3A). The rightmost lane (pPmr3) shows a positive control using pPmr3 plasmid DNA as the template. Lane M refers to the molecular weight marker. (D) RT-PCR analysis of aphVIII expression. RNA from paromomycinresistant transformants was reverse transcribed and products were amplified by PCR using primers specific for the aphVIII gene construct. Transformants with aphVIII expression were expected to yield a 324-bp cDNA fragment (Figure 3A). The parent wild-type strain was used as a control. Lane M, molecular weight marker. (E) Sequence obtained from the amplified and cloned genomic and cDNA fragments. The 324-bp fragment contains part of the aphVIII gene and part of the $5^{\prime}$ untranslated region from $\mathrm{V}$. carteri rbcS3. The positions of the primers and the start codon (bold) are indicated. 

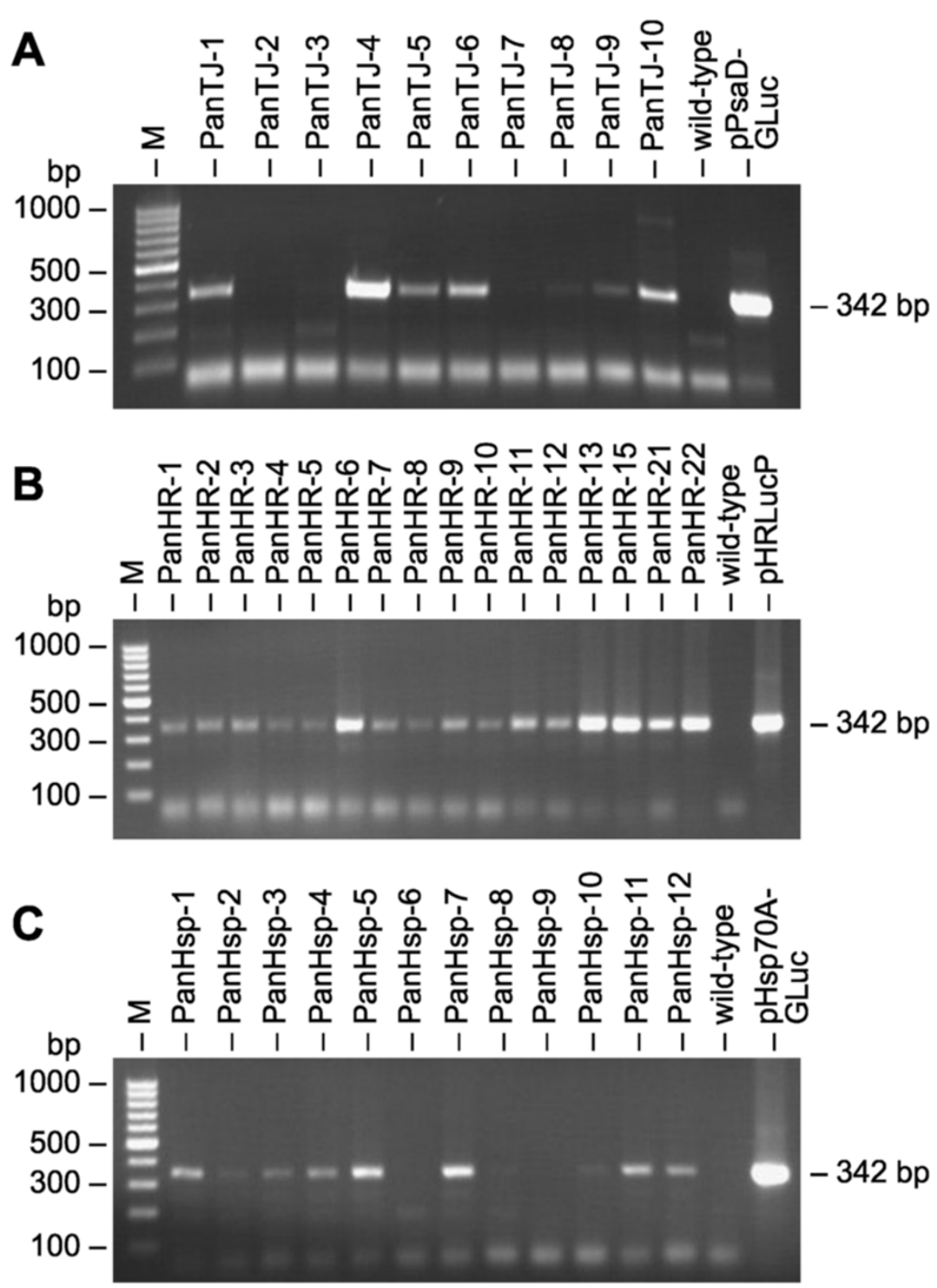

D

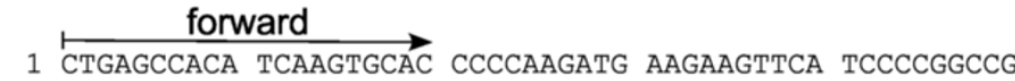

51 CTGCCACACC TACGAGGGCG ACAAGGAGAG CGCCCAGGGC GGCATCGGCG

101 AGGCCATCGT GGACATCCCC GAGATCCCCG GCTTCAAGGA CCTGGAGCCC

151 ATGGAGCAGT TCATCGCCCA GGTGGACCTG TGCGTGGACT GCACCACCGG

201 CTGCCTGAAG GGCCTGGCCA ACGTGCAGTG CAGCGACCTG CTGAAGAAGT

251 GGCTGCCCCA GCGCTGCGCC ACCTTCGCCA GCAAGATCCA GGGCCAGGTG

301 GACAAGATCA AGGGCGCCGG CGGCGACGAT ACGTAAGGAT CC

Figure 5 Demonstration of co-transformation of heterologous genes. Paromomycin-resistant transformants were analyzed for the presence of the co-transformed, non-selectable DNA in the genome. PCRs were conducted using genomic DNA from transformants co-transformed with the pPsaD-GLuc (A), pHRLuCP (B) or pHsp70A-GLuc (C) plasmids as template. The parental wild-type strain was analyzed as a control. Primers were specific for the heterologous gluc gene, and a 342-bp PCR fragment (Figure 3B-D) was expected in co-transformants. The rightmost lane shows a positive control using DNA of the co-transformed plasmid as the template. Lane M refers to the molecular weight marker. (D) Sequence obtained from the amplified and cloned gluc fragments. Primer positions, the stop codon (bold), and a BamHI restriction site (italics) are indicated. 


\section{A luciferase activity of pPsaD-GLuc-derived transformants}

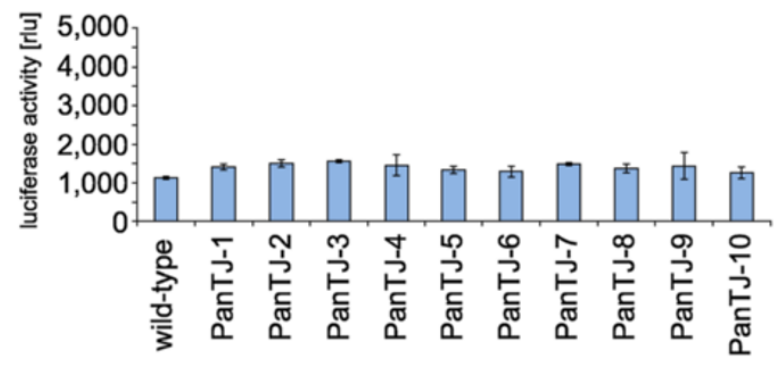

B luciferase activity of pHRLucP-derived transformants

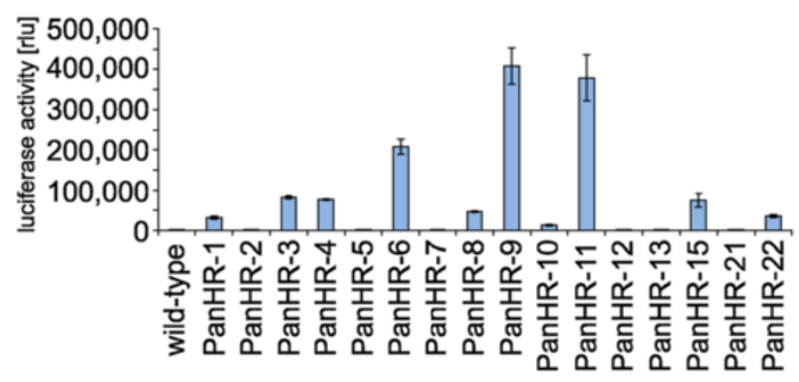

\section{C luciferase activity of pHsp70A-GLuc-derived transformants}

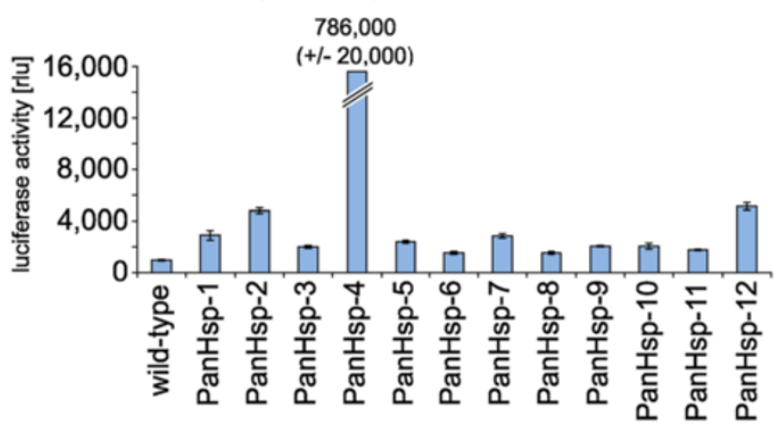

D fold induction of luciferase activity after heat shock

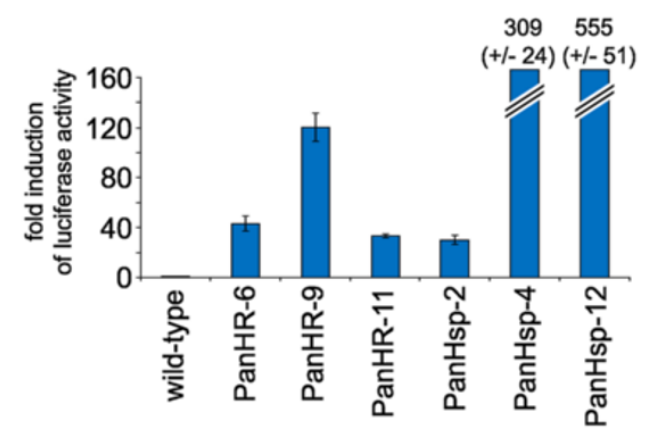

Figure 6 Quantification and inducibility of luciferase activity in transformants expressing the luciferase gene. Luciferase activity in transformants was assayed using a luminometer. The bars represent the mean of three independent experiments. The standard deviation is indicated. (A) Luciferase activity of pPsaD-GLuc derived transformants (PanTJ...) compared to the wild-type strain. (B) Luciferase activity of pHRLucP derived transformants (PanHR...) compared to the wild-type strain. (C) Luciferase activity of pHsp70A-GLuc derived transformants (PanHsp...) compared to the wild-type strain. (D) Fold induction of luciferase activity in heat-shocked transformants $\left(39^{\circ} \mathrm{C}\right)$ compared to non-heat-shocked transformants. In pHRLucP-derived transformants (PanHR...) the luciferase is driven by the V. carteri hsp70A/rbcS3 tandem promoter. For pHsp70A-GLuc-derived transformants (PanHsp...) the luciferase gene is driven by the C. reinhardtii HSP70A promoter. The parental wild-type strain was analyzed as a control. Transformants and wild-type colonies were subjected to a temperature shift from $29^{\circ} \mathrm{C}$ to $39^{\circ} \mathrm{C}$ for $1 \mathrm{~h}$. After a 15 min recovery phase at $29^{\circ} \mathrm{C}$, cells were lysed, and luciferase activity was assayed. As a reference control, non-heat-shocked transformants were analyzed in an identical fashion. 
temperature shift. The temperature was changed from $29^{\circ} \mathrm{C}$ to 9 different temperatures between $27^{\circ} \mathrm{C}$ and $51^{\circ} \mathrm{C}$. The strongest increase in luciferase activity was achieved by a temperature shift to $39^{\circ} \mathrm{C}$ for $1 \mathrm{~h}$. In extracts of transformants generated by co-transformation with plasmid pHRLucP the luciferase activity increased between 33and 120 -fold compared to algae that were kept at $29^{\circ} \mathrm{C}$. Extracts of transformants generated by co-transformation with plasmid pHsp70A-GLuc showed a 30- to 555-fold increase in luciferase activity (Figure 6D).

The heat-inducibility of luciferase activity also was investigated by an assay using light sensitive films and intact, undisrupted cells. For it, an aliquot of the transformant cells produced with plasmid pHRLucP was subject to a temperature shift from $29^{\circ} \mathrm{C}$ to $39^{\circ} \mathrm{C}$ for $1 \mathrm{~h}$; as a reference, another aliquot of the transformant cells was kept at $29^{\circ} \mathrm{C}$. The aliquots were pipetted into separate wells of a 24-well microtiter plate, substrate solution was added and the plates were set down on a light sensitive film for $2 \mathrm{~h}$ in the dark. In heat-treated transformants, the light emission caused by luciferase activity was strong enough to turn the light sensitive film totally black (Figure 7). No signal was detectable in transformants that were not subject to the increase in temperature. As expected, both untreated and heat-treated wild-type cells also show no signal.

The molecular weight of the mature Gluc protein in P. morum was determined by comparison with a molecular weight marker in an in-gel activity assay. For it, cell extracts of heat induced transformants and controls were separated on a standard SDS-PAGE without thiol reagents. After electrophoresis, SDS was removed from the gel to allow for refolding of the luciferase enzyme into its active conformation. After addition of the substrate solution, the gel was set down on a light sensitive film for $2 \mathrm{~h}$ in the dark.

In cell extracts from heat-treated transformants, generated by co-transformation with plasmid pHRLucP (Figure 8, transformant PanHR-11), light emission produced a band with a size of about $20 \mathrm{kDa}$ that reflects the molecular weight of the Gluc protein (Figure 8). For transformants generated by co-transformation with plasmid pHsp70AGLuc, a size of $31 \mathrm{kDa}$ was calculated for the intact, unprocessed HSP70B/Gluc fusion protein. The in-gel activity assay loaded with cell extracts from heat-treated transformants (Figure 8, transformant PanHsp-4) shows a band of only about $20 \mathrm{kDa}$. This size reveals that the HSP70B chloroplast transit peptide has been cleaved off as expected.

The results from the in-gel activity assays substantiate the heat-inducibility of heat-shock promoters from heterologous sources in P. morum.

Long term stability of DNA integration and gene expression For any biotechnological approach with transgenic organisms, the stability of the transgenes is of fundamental importance. Therefore, the stability and expression of the aphVIII and gluc genes introduced into P. morum transformants was investigated after twelve months of cultivation or, in other words, after about 300 generations. Cultivation was without selective pressure during the twelve months. The presence of the heterologous genes was rechecked by PCR and the functionality of the expression products was reexamined by paromomycin resistance assays and luminometer assays. In all transformants, PCR fragments of the expected sizes were amplified and, thus, the genomic integration of the artificial gene constructs could be confirmed by PCR. All transformants exhibited about the same antibiotic resistance compared to the values determined right after transformation; the range of fluctuations was only $+/-6 \%$. Likewise, luciferase activity in the transformants was stable. The comparison of the values after twelve months of cultivation with the values determined right after transformation gave a fluctuation range of only $+/-7 \%$. Thus, both integration and expression of the heterologous aphVIII and gluc genes are stable in P. morum.

\section{Discussion}

Here we demonstrate the stable nuclear transformation of the green alga $P$. morum by particle bombardment with plasmid-coated gold particles. Our approach only uses plasmids containing chimeric constructs from heterologous sources. Particle bombardment also was efficient for transformation of $C$. reinhardtii [40], $V$. carteri [15], G. pectorale [20] and E. elegans [11]. The capability for stable genetical modification of an organism of interest is an important requirement in modern molecular biology, because this technique facilitates the identification of gene functions and allows for the introduction of additional characteristics and abilities.

\section{Antibiotics resistance}

For stable nuclear transformation of $P$. morum the aphVIII gene of $S$. rimosus driven by a $V$. carteri hsp $70 \mathrm{~A} /$ $r b c \mathrm{~S} 3$ tandem promoter proved to be a suitable selectable marker, even though all parts of the DNA construct came from heterologous sources. Transformants generated with the aphVIII construct show an up to 333-fold higher tolerance to the aminoglycoside antibiotic paromomycin compared to the parent wild-type strain. When the aphVIII gene was used as a selectable marker in other volvocine algae, the factor for the increase in antibiotic tolerance in transformants was similar or lower. For $V$. carteri the increase in antibiotic tolerance was about 100-fold [30,31], it was 100 to 200 fold in C. reinhardtii [25,30], about 330-fold in E. elegans [11] and 15 to 40 fold in G. pectorale [20]. Even if the antibiotic tolerance of transformants varies between the investigated volvocine species, 


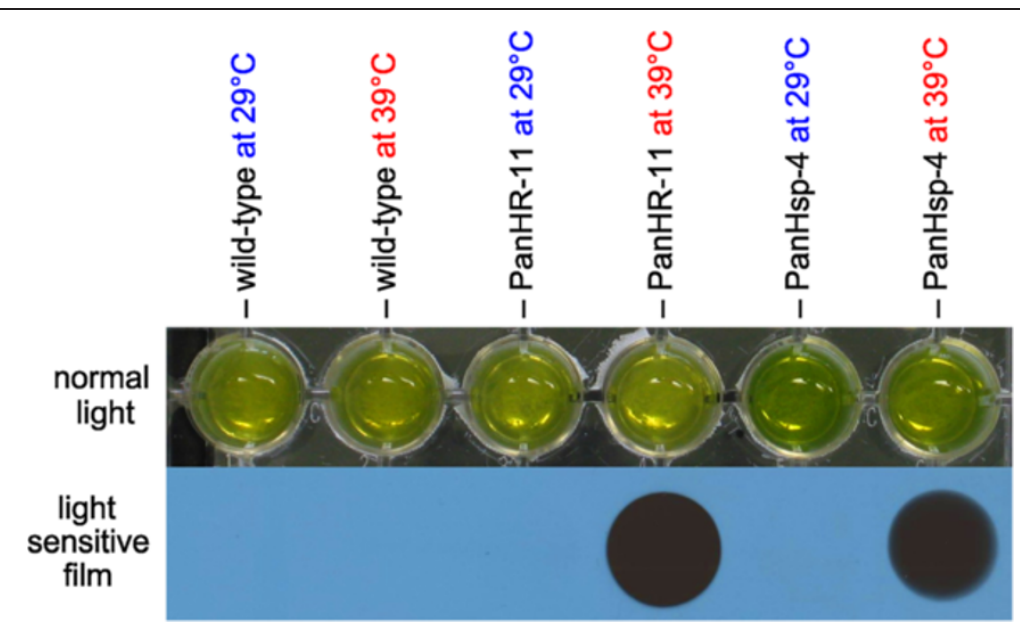

Figure 7 Visualization of inducible luciferase activity. Luciferase assay results for parental wild-type colonies and for several transformants with or without heat shock. The transformants PanHR-11 and PanHsp-4 were generated with the co-bombarded plasmids pHRLucP and pHsp70A-GLuc, respectively. Algae cultures were divided into two aliquots; one aliquot was subjected to a heat shock at $39^{\circ} \mathrm{C}$ for $1 \mathrm{~h}$, and the other aliquot was maintained at $29^{\circ} \mathrm{C}$. Upper row: standard photo showing the assay setup (normal light). Lower row: exposure to a light-sensitive film.

the aphVIII gene allowed for selection of transformants in all these species.

\section{Transformation frequency}

The frequency of transformation was calculated to be 1.2 $\times 10^{-6}$ per cell in $P$. morum. The transformation frequency in $V$. carteri was estimated to be $2.5 \times 10^{-5}$ [15]. In C. reinhardtii the frequency of transformation was 1.3 $1.9 \times 10^{-7}[41]$; it was $1.1-6.6 \times 10^{-7}$ in G. pectorale [20] and $3.7 \times 10^{-7}$ in E. elegans [11]. Thus, the transformation frequency in $P$. morum is about 20 times lower than in $V$. carteri but about 2 to 10 times higher than in C. reinhardtii, G. pectorale and E. elegans. On an overall basis, the transformation frequencies in volvocine algae vary by about two orders of magnitude $\left(1.1 \times 10^{-7}\right.$ to $\left.2.5 \times 10^{-5}\right)$. There is limited information about transformation frequencies in other algae with the exception of some diatom species. The reported frequencies are $1 \times 10^{-7}-1 \times 10^{-6}$

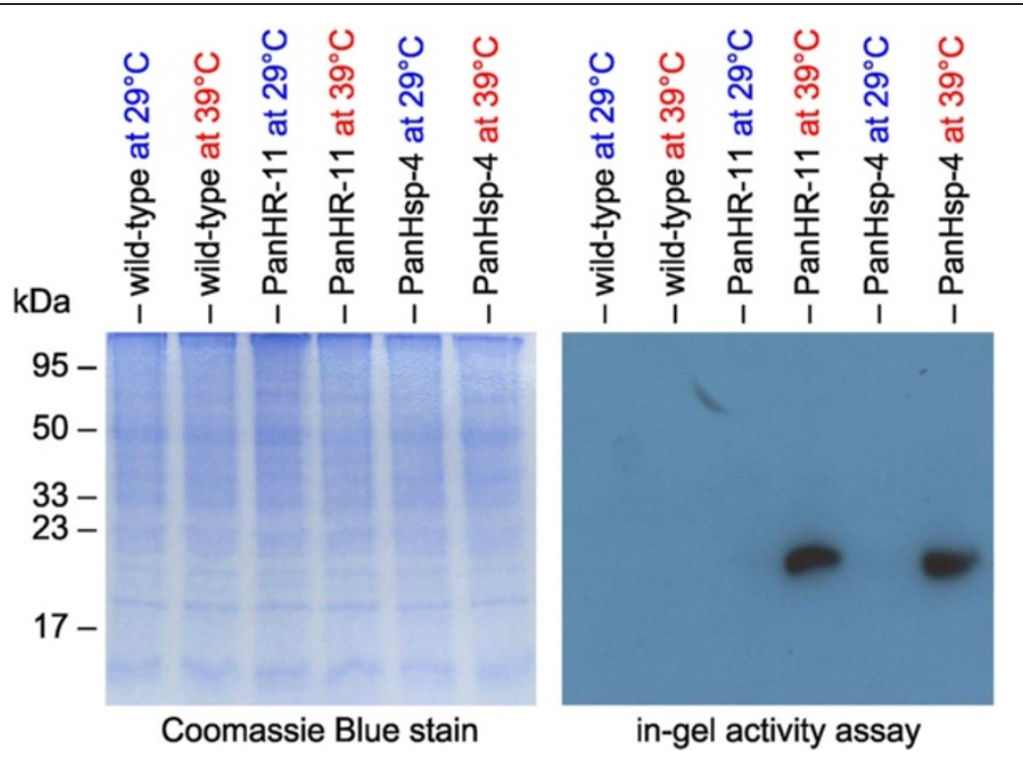

Figure 8 Detection of luciferase activity by in-gel activity assays. The transformants PanHR-11 and PanHsp-4 were generated with the co-bombarded plasmids PHRLuCP and pHsp70A-GLuc, respectively. The wild-type strain was used as a control. Algae cultures were divided into two aliquots; one aliquot was subjected to a heat shock at $39^{\circ} \mathrm{C}$ for $1 \mathrm{~h}$, and the other aliquot was maintained at $29^{\circ} \mathrm{C}$. Cell extracts with equal amounts of protein were subjected to SDS-PAGE. Subsequently, in-gel renaturation was performed using $\beta$-cyclodextrin to remove SDS from the gel, the coelenterazine-substrate was added, and the gel was exposed to a light-sensitive film (right panel). As a loading control, the same extracts were also stained with Coomassie Blue following SDS-PAGE (left panel). 
per cell in Phaeodactylum tricornutum [42] and $3 \times 10^{-8}$ $3 \times 10^{-7}$ per cell in Cyclotella cryptica and Navicula saprophila [43]. Therefore, in diatoms the frequency of transformation is similar or somewhat lower compared to that in volvocine algae.

\section{Co-transformation rate}

Co-transformation of a selectable marker plasmid and the gene of interest on a separate plasmid is a common strategy especially when large genes and complex gene constructs have to be integrated into the genome $[16,20,24,26,29,31,44-46]$. Another advantage of cotransformation is that the same selectable marker plasmid can be used for all transformation experiments. In $P$. morum the co-transformation rate was calculated to be at about $80 \%$. For $V$. carteri co-transformation rates of $10 \%-60 \%$ [29] or $40 \%-80 \%$ [15] have been reported. The co-transformation rate was about $80 \%$ in C. reinhardtii [26], 30\% - 50\% in G. pectorale [20] and $50 \%-100 \%$ in E. elegans [11]. The co-transformation rates in volvocine algae are high in all volvocine species and particularly in P. morum. Therefore, transformation of $P$. morum does not require construction of vectors that contain all required genes and regulatory elements on a single plasmid.

\section{Expression of heterologous genes using heterologous promoters}

Some promoters from $C$. reinhardtii have been shown to work in $V$. carteri and vice versa [30]. Likewise, some promoter elements from $C$. reinhardtii and $V$. carteri also work in G. pectorale and E. elegans $[11,20]$. Here we show for P. morum that both the heterologous hsp70A/ rbcS3 tandem promoter of $V$. carteri and the heterologous HSP70A promoter of $C$. reinhardtii work in this species. Three out of the four constructs clearly lead to functional expression of the heterologous Gluc luciferase and the heterologous aminoglycoside 3'-phosphotransferase VIII (AphVIII) enzymes. It is unclear why transformants produced with pPsaD-GLuc (PanTJ...) didn't produce significant luciferase activity.

The heterologous heat shock promoters retained their inducibility by heat when expressed in P. morum. The expression was up to 555 times higher in heat-shocked versus non-heat-shocked cultures.

\section{Conclusion}

The introduction of foreign genes into the nuclear genome of $P$. morum by particle bombardment is now feasible. Both the heterologous $h s p 70 \mathrm{~A} / r b c \mathrm{~S} 3$ tandem promoter of $V$. carteri and the heterologous HSP70A promoter of $C$. reinhardtii drive the expression of heterologous genes in $P$. morum. Both promoters retained their heatinducibility in P. morum. Furthermore, the heterologous
aphVIII gene of $S$. rimosus was established as a selectable marker and the gluc luciferase gene was found to be a useful reporter gene in P. morum. It is thus to be emphasized that genetic engineering of a species is possible even without the availability of any endogenous genes and promoters.

\section{Methods}

\section{Strains and culture conditions}

The wild-type $P$. morum strain SAG 32.96 was obtained from the Culture Collection of Algae at Goettingen University (SAG), Germany. Cultures were maintained in Jaworski medium (JM) [47] at $29^{\circ} \mathrm{C}$ in an $8 \mathrm{~h}$ dark $/ 16 \mathrm{~h}$ light $(\sim 10,000$ lux $)$ cycle $[11,20]$. Cultures were grown in $10 \mathrm{ml}$ glass tubes, 50 or $300 \mathrm{ml}$ Erlenmeyer flasks, or $1,000 \mathrm{ml}$ Fernbach flasks. The glass tubes had caps that allow for gas exchange, and Erlenmeyer and Fernbach flasks were aerated via Pasteur pipettes with approximately $50 \mathrm{~cm}^{3}$ sterile air/min [11,20]. Transgenic strains that express the aphVIII gene were grown in JM in the presence of $1 \mu \mathrm{g}$ paromomycin/ml (paromomycin sulfate, Sigma-Aldrich, St. Louis, MO).

\section{Transformation vectors}

The pPmr3 plasmid (Figure 3A) contains the $0.8 \mathrm{~kb}$ coding region of the $S$. rimosus aphVIII selectable marker gene, a $V$. carteri hsp70A-rbcS3 tandem promoter $(0.5 \mathrm{~kb}$ of $V$. carteri $h s p 70 \mathrm{~A}$ and $0.27 \mathrm{~kb}$ of $V$. carteri $r b c \mathrm{~S} 3$ sequences), the 3' UTR from the $V$. carteri rbcS3 gene ( $0.53 \mathrm{~kb}$ of downstream sequence), and the pBluescript II vector backbone [GenBank: AY429514] [31]. The total size of the pPmr3 plasmid is $5.1 \mathrm{~kb}$.

The pPsaD-GLuc plasmid (Figure 3B) contains the $0.57 \mathrm{~kb}$ coding region of the luciferase ( $g l u c)$ gene from G. princeps, which was engineered to match the codon usage in $C$. reinhardtii, $0.8 \mathrm{~kb}$ of upstream sequence, which includes the $C$. reinhardtii PSAD promoter, the 3 '-UTR of the C. reinhardtii psaD gene $(0.56 \mathrm{~kb}$ of downstream sequence), and the pBluescript vector backbone [27,36] [GenBank: EU372000, AF335592]. The pPsaDGLuc plasmid is $5.0 \mathrm{~kb}$ in size.

The pHsp70A-GLuc plasmid (Figure 3C) contains the $0.57 \mathrm{~kb}$ coding region of the luciferase $(\mathrm{gluc})$ gene from G. princeps (codon-optimized for C. reinhardtii) [27] fused downstream of a $0.8 \mathrm{~kb}$ genomic DNA fragment that contains the first three exons and two introns of the $H S P 70 B$ gene of $C$. reinhardtii; this fragment of the $H S P 70 B$ gene contains the sequence coding for the chloroplast transit peptide of HSP70B. The hybrid HSP70B/gluc gene is driven by the $C$. reinhardtii HSP70A promoter $(0.26 \mathrm{~kb}$ of upstream sequence) and the $3^{\prime}$ UTR comes from the $C$. reinhardtii $R B C S 2$ gene ( $0.22 \mathrm{~kb}$ of downstream sequence) [27]. The total size of the pHsp70A-GLuc plasmid is $4.9 \mathrm{~kb}$. 
The pHRLucP plasmid (Figure 3D) contains the $0.57 \mathrm{~kb}$ coding region of the luciferase (gluc) gene of G. princeps, which was engineered to match the codon usage in C. reinhardtii, the $V$. carteri hs $p 70 \mathrm{~A}-r b c \mathrm{~S} 3$ tandem promoter $(0.5 \mathrm{~kb}$ of $V$. carteri $h s p 70 \mathrm{~A}$ and $0.27 \mathrm{~kb}$ of $V$. carteri rbcS3 sequences), the $C$. reinhardtii PSAD 3' UTR (0.55 $\mathrm{kb}$ of downstream sequence), and the pBluescript II vector backbone $[11,27,36]$. The pHRLucP plasmid is $5.0 \mathrm{~kb}$ in size.

\section{Preparation of plasmid DNA}

Plasmid DNA was purified using the Nucleospin ${ }^{\circ}$ Plasmid Kit according to the manufacturers' instructions (MachereyNagel, Düren, Germany).

\section{Coating of microprojectiles}

Gold microprojectiles $(0.6 \mu \mathrm{m}$ in diameter, Bio-Rad, Hercules, CA) were coated with the required plasmids for biolistic transformation as previously described $[11,20]$. The DNA-coated microprojectiles were resuspended in $60 \mu \mathrm{l}$ of ethanol and kept at $4^{\circ} \mathrm{C}$; these microprojectiles were used within $3 \mathrm{~h}$ of preparation.

\section{Determination of cell concentration}

In $P$. morum the number of cells per colony varies. Therefore, we refer to "cells/ml" rather than "colonies/ $\mathrm{ml}$ ". The concentration of cells was determined using a hemacytometer with Neubauer ruling.

\section{Stable nuclear transformation by particle bombardment}

The stable transformation of $P$. morum was performed using a Biolistic ${ }^{\circ}$ PDS-1000/He (Bio-Rad) particle gun. To this end, a logarithmically growing $P$. morum culture $(150 \mathrm{ml})$ at a cell concentration of $\sim 7 \times 10^{4}$ cells $/ \mathrm{ml}$ was harvested by centrifugation $(1,000 \mathrm{~g}, 5 \mathrm{~min}$, swing-out rotor) and resuspended in $6 \mathrm{ml}$ of JM. One milliliter of the suspension was evenly spread on a cellulose acetate membrane filter and excess liquid was removed as previously described $[11,20]$. One-sixth of the DNA-coated microprojectiles were evenly spread on a macrocarrier (Bio-Rad) that was placed in a macrocarrier holder (BioRad). The transformation procedure was as previously described $[11,20]$ and the most successful combination of parameters is shown in Table 1. After the bombardment step, the algae were washed off from the membrane filter with JM. The procedure was repeated five times and the algae from six rounds of bombardment were pooled and then evenly distributed among twelve $50 \mathrm{ml}$ Erlenmeyer flasks containing a volume of $\sim 40 \mathrm{ml}$ of JM. The bombarded colonies were incubated under standard conditions for $24 \mathrm{~h}$ to allow for regeneration and expression of the transgenes. Then, $2 \mu$ g of paromomy$\mathrm{cin} / \mathrm{ml}$ was added. The large fraction of non-transformed cells died within $48 \mathrm{~h}$ and the medium clarified. After
10-14 days of incubation in the presence of antibiotic, re-greening of flasks indicated the initial presence and reproduction of at least one paromomycin-resistant P. morum transformant that led to a population of transformants. No more than one transformant per flask was analyzed $[11,20]$.

\section{Re-isolation of transformants}

Transformants were re-isolated to ensure uniform genetic conditions for all further analyses. For this purpose, a serial dilution of an exponentially growing $P$. morum culture was performed in a Terasaki plate $\left(\mathrm{Nunc}^{\mathrm{Tw}}\right.$ MicroWell $^{\mathrm{Tm}}$ MiniTrays; Thermo Fisher Scientific, Langenselbold, Germany) $[11,20]$. Each well of the Terasaki plate was filled with $10 \mu \mathrm{l}$ of JM. A single P. morum colony was finally transferred into a standard glass tube with JM, containing $1 \mu \mathrm{g}$ of paromomycin/ml. Further incubation was under standard conditions.

\section{Paromomycin-resistance assay}

Cells of transformed or wild-type $P$. morum strains were transferred into the wells of a 24-well culture plate (Sarstedt, Nümbrecht, Germany) with a wide range of paromomycin concentrations from 0 to $100 \mu \mathrm{g} / \mathrm{ml}$ in $1 \mathrm{ml} \mathrm{JM}$ (concentrations are given in Figure 2). At the beginning of the assay, each well contained approximately 4,000 cells, which corresponds to 250-300 colonies. After incubation under standard conditions for 12 days, the wells were analyzed for viable green cells or white remains of lysed cells.

\section{Primer design}

Oligonucleotide primers were designed using the primer analysis software Oligo 6 (Molecular Biology Insights, Cascade, CO), DNASIS ${ }^{\text {tm }}$ (version 7.00; Hitachi Software Engineering, San Francisco, CA), and Primer Express ${ }^{\circ}$ (Applied Biosystems, Foster City, CA).

\section{Isolation of genomic DNA}

Ten milliliters of a logarithmically growing $P$. morum culture with a density of $6 \times 10^{6}$ cells/ml was harvested by centrifugation $(3,500 \mathrm{~g}$ for $10 \mathrm{~min})$. The resulting pellet, which had a wet weight of $\sim 80 \mathrm{mg}$, was washed with water and resuspended in $40 \mu \mathrm{l}$ water. Isolation of genomic DNA was as previously described $[11,20]$.

\section{Genomic PCR}

PCR reactions with genomic DNA as a template were carried out in a total volume of $50 \mu$ l that contained 100 ng of genomic DNA, $300 \mathrm{nM}$ of each primer, $0.2 \mathrm{mM}$ dNTP, $1.5 \mathrm{mM} \mathrm{MgCl}_{2}$, and 2.6 units of Expand High Fidelity enzyme mix in 1× Expand High Fidelity buffer (Roche Applied Science, Basel, Switzerland). The PCR reactions were performed on a T3 Thermocycler 
PCR system (Biometra, Göttingen, Germany) using the following conditions: 40 cycles of $94^{\circ} \mathrm{C}$ for $20 \mathrm{~s}, 55^{\circ} \mathrm{C}$ for $30 \mathrm{~s}$, and $72^{\circ} \mathrm{C}$ for $45 \mathrm{~s}$ and a final extension was at $72^{\circ} \mathrm{C}$ for $10 \mathrm{~min}$. The PCR products were cloned and sequenced (Eurofins, Ebersberg, Germany).

\section{Isolation of total RNA}

Total RNA was extracted from $\sim 100 \mathrm{mg}$ of concentrated, frozen $P$. morum algae using $1 \mathrm{ml}$ of phenolbased TRI Reagent (Sigma-Aldrich, St. Louis, MO) and $300 \mu$ trichloromethane. RNA precipitation and RNA purification was as previously described $[11,20]$.

\section{Reverse Transcription (RT)-PCR}

First strand cDNA synthesis was carried out using $1 \mu \mathrm{g}$ of total RNA and Moloney murine leukemia virus (MMLV) reverse transcriptase lacking ribonuclease $\mathrm{H}$ activity ( $\mathrm{H}$ minus) according to the manufacturer's instructions (Promega). The subsequent PCR step was performed using the Expand High Fidelity PCR system (Roche Applied Science, Basel, Switzerland), a T3 Thermocycler PCR system (Biometra), and the following cycling conditions: 40 cycles of $94^{\circ} \mathrm{C}$ for $20 \mathrm{~s}, 55^{\circ} \mathrm{C}$ for $30 \mathrm{~s}$, and $72^{\circ} \mathrm{C}$ for $45 \mathrm{~s}$ and a final extension at $72^{\circ} \mathrm{C}$ for $10 \mathrm{~min}$. The RT-PCR products were cloned and sequenced.

\section{Induction of luciferase activity}

Preliminary tests showed that the shift of a $P$. morum culture $\left(3-6 \times 10^{5}\right.$ cells $\left./ \mathrm{ml}\right)$ from $29^{\circ} \mathrm{C}$ to $39^{\circ} \mathrm{C}$ for $1 \mathrm{~h}$, followed by a recovery phase at $29^{\circ} \mathrm{C}$ for $15 \mathrm{~min}$, leads to the strongest induction of luciferase activity in the temperature range investigated $\left(27^{\circ} \mathrm{C}\right.$ to $\left.51^{\circ} \mathrm{C}\right)$.

\section{Luciferase assays}

For assays on light-sensitive films, $P$. morum cultures with a cell density of $3-6 \times 10^{5}$ cells $/ \mathrm{ml}$ were divided into aliquots of $50 \mathrm{ml}$. One aliquot was incubated at the optimal temperature for heat stress-induced expression of luciferase $\left(39^{\circ} \mathrm{C}\right)$ for $1 \mathrm{~h}$, and another aliquot was incubated at $29^{\circ} \mathrm{C}$ as a reference control. Further treatment and execution of the luciferase enzyme assay was as previously described $[11,20]$. The final exposure to a chemiluminescence sensitive film (Retina XBA; Fotochemische Werke) was for $2 \mathrm{~h}$ at $20^{\circ} \mathrm{C}[11,20,35]$.

The quantification of luciferase activity was conducted as previously described [20,27] using a MiniLumat LB9506 luminometer (Berthold, Bad Wildbad, Germany). For this purpose, aliquots of a P. morum culture (3-6 $\times$ $10^{5} \mathrm{cells} / \mathrm{ml}$ ) were heat-stressed at $39^{\circ} \mathrm{C}$ or kept at $29^{\circ} \mathrm{C}$ (control), respectively. Further treatment was as previously described [20]. Luminescence was recorded as relative light units (rlu). Induction factors were calculated by comparison of samples from heat-shocked versus non-heatshocked cultures.

\section{In-gel activity assay}

One liter of logarithmically growing, heat-stressed or untreated cultures of transformed or wild-type $P$. morum cultures with cell densities of $4-7 \times 10^{5}$ cells $/ \mathrm{ml}$ were harvested by filtration on a $10-\mu \mathrm{m}$ mesh nylon screen. Cells passing the screen were harvested by centrifugation $(4,000 \mathrm{~g}, 5 \mathrm{~min})$ and added to cells collected on the screen. Cells lysates were produced as previously described [11]. The protein concentration of the cell extracts was determined photometrically using the Bio-Rad Protein Assay Dye Reagent (Bio-Rad). For gel electrophoresis, $50 \mu \mathrm{g}$ of total protein was loaded onto a standard SDS-polyacrylamide gel. The gel electrophoresis, the in-gel renaturation, the execution of the luciferase enzyme assay and the light detection on a chemiluminescence sensitive film was performed as previously described [11].

\section{Additional file}

Additional file 1: Influence of different parameters on transformation efficiency.

\section{Abbreviations}

aphVIII: S. rimosus aminoglycoside 3'-phosphotransferase VIII gene; GFP: Green fluorescent protein; gluc: G. princeps luciferase gene (adapted to C. reinhardtii nuclear codon usage); hsp70A: Heat shock protein 70A gene; JM: Jaworski medium; kDa: Kilodalton; MMLV: Moloney murine leukemia virus; PCR: Polymerase chain reaction; PSAD: Abundant protein of photosystem I complex gene; rbcS3: Ribulose bisphosphate carboxylase small chain gene 3; rlu: Relative light units; RT: Reverse transcription; SDS: Sodium dodecyl sulfate; UTR: Untranslated region.

\section{Competing interests}

The authors declare that they have no competing interests.

\section{Authors' contributions}

$\mathrm{KL}$ conducted the experiments, analyzed the data, and wrote the first version of the manuscript with advice and guidance from $\mathrm{AH}$. $\mathrm{AH}$ (corresponding author) conceived and coordinated the study, critically evaluated the data, and finalized the manuscript. Both authors read and approved the final manuscript.

\section{Acknowledgements}

We are grateful to T. Jakobiak and R. Schmitt (University of Regensburg, Germany) for providing the aphVIII gene, to N. Shao and R. Bock (Max-PlanckInstitut für Molekulare Pflanzenphysiologie, Potsdam-Golm, Germany) for providing the gluc gene, and to K. Puls for technical assistance. We acknowledge the support of the Deutsche Forschungsgemeinschaft and the Open Access Publication Funds of Bielefeld University, which funded the article processing charges.

Received: 31 March 2014 Accepted: 11 July 2014

Published: 17 July 2014

\section{References}

1. Herron MD, Hackett JD, Aylward FO, Michod RE: Triassic origin and early radiation of multicellular volvocine algae. Proc Natl Acad Sci U S A 2009, 106(9):3254-3258.

2. Kirk DL: Volvox: Molecular-Genetic Origins of Multicellularity and Cellular Differentiation. 1st edition. Cambridge: Cambridge University Press; 1998.

3. Höhn S, Hallmann A: There is more than one way to turn a spherical cellular monolayer inside out: type B embryo inversion in Volvox globator. BMC Biol 2011, 9(1):89. 
4. Hallmann A: Evolution of reproductive development in the volvocine algae. Sex Plant Reprod 2011, 24:97-112.

5. Harris EH, Stern DB, Witman GB: The Chlamydomonas Sourcebook (2nd Edition). 2nd edition. San Diego, CA: Academic Press; 2009.

6. Fulton $\mathrm{AB}$ : Colonial development in Pandorina morum. II. Colony morphogenesis and formation of the extracellular matrix. Dev Biol 1978, 64(2):236-251

7. Lamouroux JV, de Saint-Vincent JBGM B, Deslongschamps E: Encyclopédie méthodique ou par ordre de matières. Histoire naturelle des zoophytes, ou animaux rayonnés, faisant suite à l'histoire naturelle des vers de Bruguière. Paris: Chez Mme Veuve Agasse; 1824.

8. Herron MD, Michod RE: Evolution of complexity in the volvocine algae: transitions in individuality through Darwin's eye. Evolution 2008, 62(2):436-451.

9. Nozaki $H$, Kuroiwa $T$ : Ultrastructure of the extracellular matrix and taxonomy of Eudorina, Pleodorina and Yamagishiella gen. nov. (Volvocaceae, Chlorophyta). Phycologia 1992, 31(6):529-541.

10. Nozaki H, Kazaki H: The sexual process of Japanese Pandorina morum Bory (Chlorophyta). J Jpn Bot 1979, 54(12):363-370.

11. Lerche K, Hallmann A: Stable nuclear transformation of Eudorina elegans. BMC Biotechnol 2013, 13:11.

12. Moore $L$, Coleman AW: The linear $20 \mathrm{~kb}$ mitochondrial genome of Pandorina morum (Volvocaceae, Chlorophyta). Plant Mol Biol 1989, 13(4):459-465.

13. Merchant SS, Prochnik SE, Vallon O, Harris EH, Karpowicz SJ, Witman GB, Terry A, Salamov A, Fritz-Laylin LK, Marechal-Drouard L, Marshall WF, Qu LH, Nelson DR, Sanderfoot AA, Spalding MH, Kapitonov W, Ren Q, Ferris P, Lindquist E, Shapiro H, Lucas SM, Grimwood J, Schmutz J, Cardol P, Cerutti H, Chanfreau G, Chen CL, Cognat V, Croft MT, Dent R, et al: The Chlamydomonas genome reveals the evolution of key animal and plant functions. Science 2007, 318(5848):245-250.

14. Prochnik SE, Umen J, Nedelcu AM, Hallmann A, Miller SM, Nishii I, Ferris P, Kuo A, Mitros T, Fritz-Laylin LK, Hellsten U, Chapman J, Simakov O, Rensing SA, Terry A, Pangilinan J, Kapitonov V, Jurka J, Salamov A, Shapiro H, Schmutz J, Grimwood J, Lindquist E, Lucas S, Grigoriev IV, Schmitt R, Kirk D, Rokhsar DS, Hellsten U, Chapman J, et al: Genomic analysis of organismal complexity in the multicellular green alga Volvox carteri. Science 2010, 329(5988):223-226.

15. Schiedlmeier B, Schmitt R, Müller W, Kirk MM, Gruber H, Mages W, Kirk DL: Nuclear transformation of Volvox carteri. Proc Natl Acad Sci U S A 1994, 91(11):5080-5084

16. Kindle KL: High-frequency nuclear transformation of Chlamydomonas reinhardtii. Proc Natl Acad Sci U S A 1990, 87(3):1228-1232.

17. Klein RM, Wolf ED, Wu R, Sanford JC: High-velocity microprojectiles for delivering nucleic acids into living cells. 1987. Biotechnology 1992, 24:384-386.

18. Brown LE, Sprecher SL, Keller LR: Introduction of exogenous DNA into Chlamydomonas reinhardtii by electroporation. Mol Cell Biol 1991, 11(4):2328-2332.

19. Kumar SV, Misquitta RW, Reddy VS, Rao BJ, Rajam MV: Genetic transformation of the green alga Chlamydomonas reinhardtii by Agrobacterium tumefaciens. Plant Sci 2004, 166:731-738.

20. Lerche K, Hallmann A: Stable nuclear transformation of Gonium pectorale. BMC Biotechnol 2009, 9(1):64.

21. Nelson JA, Savereide PB, Lefebvre PA: The CRY1 gene in Chlamydomonas reinhardtii: structure and use as a dominant selectable marker for nuclear transformation. Mol Cell Biol 1994, 14(6):4011-4019.

22. Randolph-Anderson BL, Sato R, Johnson AM, Harris EH, Hauser CR, Oeda K, Ishige F, Nishio S, Gillham NW, Boynton JE: Isolation and characterization of a mutant protoporphyrinogen oxidase gene from Chlamydomonas reinhardtii conferring resistance to porphyric herbicides. Plant $\mathrm{Mol} B \mathrm{BiO}$ 1998, 38(5):839-859.

23. Kovar JL, Zhang J, Funke RP, Weeks DP: Molecular analysis of the acetolactate synthase gene of Chlamydomonas reinhardtii and development of a genetically engineered gene as a dominant selectable marker for genetic transformation. Plant J 2002, 29(1):109-117.

24. Berthold P, Schmitt R, Mages W: An engineered Streptomyces hygroscopicus aph 7" gene mediates dominant resistance against hygromycin B in Chlamydomonas reinhardtii. Protist 2002, 153(4):401-412

25. Sizova I, Fuhrmann M, Hegemann P: A Streptomyces rimosus aphVIII gene coding for a new type phosphotransferase provides stable antibiotic resistance to Chlamydomonas reinhardtii. Gene 2001, 277(1-2):221-229.
26. Stevens DR, Rochaix JD, Purton S: The bacterial phleomycin resistance gene ble as a dominant selectable marker in Chlamydomonas. Mol Gen Genet 1996, 251(1):23-30

27. Shao N, Bock R: A codon-optimized luciferase from Gaussia princeps facilitates the in vivo monitoring of gene expression in the model alga Chlamydomonas reinhardtii. Curr Genet 2008, 53(6):381-388.

28. Hallmann A: Algal transgenics and biotechnology. Transgenic Plant J 2007, 1:81-98

29. Hallmann A, Rappel A: Genetic engineering of the multicellular green alga Volvox: a modified and multiplied bacterial antibiotic resistance gene as a dominant selectable marker. Plant J 1999, 17(1):99-109.

30. Hallmann A, Wodniok S: Swapped green algal promoters: aphVIII-based gene constructs with Chlamydomonas flanking sequences work as dominant selectable markers in Volvox and vice versa. Plant Cell Rep 2006, 25(6):582-591.

31. Jakobiak T, Mages W, Scharf B, Babinger P, Stark K, Schmitt R: The bacterial paromomycin resistance gene, $a p h H$, as a dominant selectable marker in Volvox carteri. Protist 2004, 155(4):381-393.

32. Davies J, Wright GD: Bacterial resistance to aminoglycoside antibiotics. Trends Microbiol 1997, 5(6):234-240.

33. Barnes AT, Case JF: Bioluminescence in the mesopelagic copepod, Gaussia princeps (T. Scott). J Exp Mar Biol Ecol 1972, 8(1):53-71.

34. Szent-Gyorgyi C, Ballou BT, Dagmal E, Bryan B: Cloning and characterization of new bioluminescent proteins. Proc SPIE 1999, 3600:4-11.

35. Jacobsen I, Hennig-Pauka I, Baltes N, Trost M, Gerlach GF: Enzymes involved in anaerobic respiration appear to play a role in Actinobacillus pleuropneumoniae virulence. Infect Immun 2005, 73(1):226-234.

36. Fischer N, Rochaix JD: The flanking regions of PsaD drive efficient gene expression in the nucleus of the green alga Chlamydomonas reinhardtii. Mol Genet Genomics 2001, 265(5):888-894.

37. Schroda M, Blöcker D, Beck CF: The HSP70A promoter as a tool for the improved expression of transgenes in Chlamydomonas. Plant J 2000 21(2):121-131.

38. Shao N, Krieger-Liszkay A, Schroda M, Beck CF: A reporter system for the individual detection of hydrogen peroxide and singlet oxygen: its use for the assay of reactive oxygen species produced in vivo. Plant J 2007, 50(3):475-487.

39. Drzymalla C, Schroda M, Beck CF: Light-inducible gene HSP7OB encodes a chloroplast-localized heat shock protein in Chlamydomonas reinhardtii. Plant Mol Biol 1996, 31(6):1185-1194.

40. Kindle KL, Schnell RA, Fernandez E, Lefebvre PA: Stable nuclear transformation of Chlamydomonas using the Chlamydomonas gene for nitrate reductase. J Cell Biol 1989, 109(6 Pt 1):2589-2601.

41. Sizova IA, Lapina TV, Frolova ON, Alexandrova NN, Akopiants KE, Danilenko VN: Stable nuclear transformation of Chlamydomonas reinhardtii with a Streptomyces rimosus gene as the selective marker. Gene 1996 181(1-2):13-18

42. Apt KE, Kroth-Pancic PG, Grossman AR: Stable nuclear transformation of the diatom Phaeodactylum tricornutum. Mol Gen Genet 1996, 252(5):572-579.

43. Dunahay TG, Jarvis EE, Roessler PG: Genetic transformation of the diatoms Cyclotella cryptica and Navicula saprophila. J Phycol 1995, 31:1004-1012.

44. Hallmann A, Sumper M: Reporter genes and highly regulated promoters as tools for transformation experiments in Volvox carteri. Proc Natl Acad Sci U S A 1994, 91(24):11562-11566.

45. Hallmann A, Sumper $\mathrm{M}$ : The Chlorella hexose $/ \mathrm{H}^{+}$symporter is a useful selectable marker and biochemical reagent when expressed in Volvox. Proc Natl Acad Sci U S A 1996, 93(2):669-673.

46. Hallmann A, Rappel A, Sumper M: Gene replacement by homologous recombination in the multicellular green alga Volvox carteri. Proc Natl Acad Sci U S A 1997, 94(14):7469-7474

47. Thompson AS, Rhodes JC, Pettman I: Culture Collection of Algae and Protozoa - Catalogue of Strains. 5th edition. Cumbria, UK: CCAP: 1988

doi:10.1186/1472-6750-14-65

Cite this article as: Lerche and Hallmann: Stable nuclear transformation of Pandorina morum. BMC Biotechnology 2014 14:65. 